Informe especial

\title{
El uso de la radiografía de tórax para la vigilancia de neumonías bacterianas en niños latinoamericanos
}

\author{
Rosanna Lagos, ${ }^{1}$ José Luis di Fabio, ${ }^{2}$ Karla Moënne, ${ }^{1}$ Alma Muñoz M., ${ }^{1}$ \\ Steven Wasserman ${ }^{3}$ y Ciro de Quadros ${ }^{4}$
}

RESUMEN La División de Vacunas e Inmunización de la Organización Panamericana de la Salud (OPS) está promoviendo la vigilancia epidemiológica de neumonías bacterianas en niños latinoamericanos, con el objetivo de generar pruebas científicas que sustenten futuras decisiones de control mediante vacunas en los países de la Región. Como es poco frecuente que el diagnóstico de estas enfermedades abarque la documentación bacteriológica del agente causal, los estudios de este tipo que se realizan en el mundo aceptan la imagen radiológica de consolidación alveolar como criterio confirmatorio de una neumonía presuntamente bacteriana.

En este informe se examinan la racionalidad teórica y los requisitos necesarios para utilizar la radiología de tórax como instrumento para la vigilancia epidemiológica de neumonías bacterianas. Además, se ofrece un resumen de las actividades realizadas en dos años de trabajo conjunto entre el Centro para Vacunas en Desarrollo, en Chile, y la División de Vacunas e Inmunización de la OPS. Durante ese período se fomentó el estudio epidemiológico de las neumonías bacterianas en niños latinoamericanos utilizando los criterios $y$ definiciones acordados a escala internacional, así como herramientas y soluciones prácticas ajustadas a la realidad de la Región. Las actividades desarrolladas hasta ahora evidencian la necesidad y factibilidad de estandarizar la interpretación de las radiografías de tórax para utilizarlas en estudios epidemiológicos.

Palabras clave Radiografía pulmonar, neumonías bacterianas, vigilancia epidemiológica.

Anualmente mueren más de cuatro millones de niños menores de 5 años en países en desarrollo a causa de

1 Centro para Vacunas en Desarrollo-Chile, Hospital de Niños Roberto del Río, Santiago, Chile. Dirección postal: Centro para Vacunas en Desarrollo-Chile, Hospital de Niños Roberto del Río (4 ${ }^{\circ}$ Piso), Avenida Zañartu 1085, Independencia, Santiago, Chile. Fax: (562) 77757 66. E-mail: rlagos@adsl. tie.cl.

2 Programa de Acceso a la Tecnología en Vacunas, División de Vacunas e Inmunización, Organización Panamericana de la Salud, Washington, EE.UU.

3 Centro para el Desarrollo de Vacunas, Universidad de Maryland, Baltimore, Maryland, EE.UU.

4 División de Vacunas e Inmunización, Organización Panamericana de la Salud, Washington, EE.UU. infecciones respiratorias agudas (IRA), especialmente neumonías (1). Aunque las causas de estas afecciones abarcan diversos patógenos bacterianos y virales, se estima que por lo menos la mitad de las neumonías graves en niños son causadas por Streptococcus pneumoniae y Haemophilus influenzae tipo b (Hib) (2). Comprensiblemente, la comunidad internacional vinculada a la salud pública ha cifrado grandes esperanzas en las vacunas conjugadas de polisacáridos contra estos dos agentes, debido a su capacidad no solo para prevenir la meningitis y otras formas de infección invasora, sino también por su potencial para controlar la morbilidad y mortalidad infantiles por neumonías bacterianas. Aun así, debido al alto precio de las vacunas conjugadas y a la necesidad de utilizar óptimamente los limitados recursos presupuestarios, las autoridades de los programas de inmunización de los países en desarrollo enfrentan un serio dilema para incorporar estas vacunas a los esquemas habituales de inmunización. El conocimiento de la carga epidemiológica de las enfermedades prevenibles mediante vacunación constituye la base fundamental para que 
estas decisiones puedan ser adoptadas de forma racional y oportuna.

Desde 1993, la División de Vacunas e Inmunización de la Organización Panamericana de la Salud (OPS) ha venido impulsando la Iniciativa Regional de Vigilancia de Meningitis y Neumonías Bacterianas, cuyo propósito es generar información epidemiológica que sirva de sustento a las decisiones de salud pública relacionadas con el uso de vacunas conjugadas en países latinoamericanos. La primera meta de la iniciativa fue instaurar una red regional de laboratorios, capacitados y coordinados por un centro de referencia, que permitiera mejorar el nivel de confirmación bacteriológica de las infecciones invasoras causadas por S. pneumoniae y Hib y profundizar en el conocimiento de los aspectos microbiológicos de estas enfermedades. Las pruebas acumuladas mediante estas iniciativas desempeñaron un importante papel en la incorporación de la vacuna conjugada contra $\mathrm{Hib}$ en los programas habituales de inmunización de los países de la Región y, más recientemente, han permitido a América Latina sobrepasar a otras regiones en desarrollo, en cuanto al conocimiento de los serotipos y la susceptibilidad a medicamentos antimicrobianos de las cepas de $S$. pneumoniae que causan infecciones invasoras en niños (3-8).

En una segunda etapa, iniciada en 1999, la Iniciativa Regional de Vigilancia de Meningitis y Neumonías se ha dedicado a impulsar actividades orientadas a documentar la importancia epidemiológica de las neumonías bacterianas en niños latinoamericanos. Aunque se reconoce que estas son provocadas mayoritariamente por Hib y S. pneumoniae, raras veces se logra aislar el microorganismo causante, por lo que $\mathrm{su}$ estudio epidemiológico exige aplicar criterios confirmatorios que complementen el diagnóstico bacteriológico. El Centro para Vacunas en Desarrollo, en Chile (CVD-Chile), fue invitado a colaborar en el diseño y desarrollo de un plan de trabajo dirigido a abordar este segundo objetivo. La participación de investigadores del CVD-Chile en un grupo con fines similares convocado por la Organización Mundial de la Salud (OMS) permitió homologar la metodología de los estudios epidemiológicos regionales con la de estudios similares que se desarrollan en otras zonas del mundo (9).

Este informe se compone de dos partes. En la primera se discuten la racionalidad teórica y los requisitos para utilizar la radiología de tórax como instrumento para la vigilancia epidemiológica de las neumonías bacterianas. En la segunda se resumen las actividades realizadas en dos años de trabajo conjunto entre el CVD-Chile y la División de Vacunas e Inmunización de la OPS, durante los cuales se fomentó el estudio epidemiológico de las neumonías bacterianas en niños latinoamericanos utilizando criterios y definiciones acordadas a escala internacional, combinadas con herramientas y soluciones prácticas ajustadas a la realidad de la Región.

\section{FUNDAMENTOS Y REQUISITOS PARA LA VIGILANCIA DE NEUMONÍAS CAUSADAS POR HIB Y STREPTOCOCCUS PNEUMONIAE}

\section{Limitaciones de los métodos bacteriológicos}

Las formas más graves de infección por Hib, S. pneumoniae y Neisseria meningitidis (meningitis, septicemia, osteo- artritis, etc.) responden a una secuen-cia patogénica común que comienza con la colonización del árbol respiratorio superior, continúa con la invasión y diseminación del agente patógeno por conducto del torrente sanguíneo $\mathrm{y}$, finalmente, culmina con la focalización secundaria del microorganismo en uno o varios órganos profundos. El agente etiológico de estas enfermedades, denominadas genéricamente de infecciones invasoras, se puede identificar mediante pruebas bacteriológicas si se realizan oportunamente hemocultivos y cultivos de otros líquidos corporales afectados. El refuerzo de la pesquisa clínica y la capacitación del personal de los laboratorios de bacteriología son fundamentales para poder abordar el estudio epidemiológico de las enfermedades invasoras causadas por cualquiera de estos agentes patógenos.

A diferencia de las infecciones invasoras, la mayoría de las neumonías causadas por $H i b$ y $S$. pneumoniae responden a un mecanismo de infección canalicular descendente $y$ pocas veces se acompañan de bacteriemia o de una infección de algún otro líquido corporal que permita aislar el agente causal (10-16). La excepción de esta regla - el cultivo del líquido obtenido mediante una punción pulmonar (16-21) - supone un procedimiento invasor que no está exento de riesgos, imposible de practicar de forma sistemática en todos los casos en que se sospecha una neumonía bacteriana. Lamentablemente, los métodos de diagnóstico microbiológico basados en la detección de antígenos o en la respuesta de anticuerpos del enfermo adolecen de dudosa especificidad (22-25) o de complejidades técnicas que limitan su utilidad en la práctica habitual (26-28). En consecuencia, la vigilancia epidemiológica de las neumonías bacterianas en niños (predominantemente causadas por Hib y S. pneumoniae) obliga a utilizar criterios confirmatorios que complementen el diagnóstico bacteriológico. Tales criterios deben ser escogidos con pragmatismo, procurando sopesar adecuadamente el interés por detectar con la mayor especificidad y sensibilidad posible el universo de casos de neumonía causada por estos agentes, sin incurrir en complejidades que limiten el estudio de los casos sospechosos o que amenacen la reproducibilidad del criterio de confirmación. Más aun, reconociendo que la neumonía infantil constituye un problema de salud pública presente en todas las regiones del mundo, es fundamental que las iniciativas de vigilancia locales se estructuren en torno a metodologías y definiciones comunes, para que la suma de estos 
esfuerzos permita delinear un panorama epidemiológico amplio y evaluar el impacto de las estrategias de control a escalas regional y mundial.

\section{La radiología de tórax}

Mientras los métodos bactriológicos no alcancen la sensibilidad necesaria, la clave de cualquier plan para la vigilancia de neumonías bacterianas radicará en lograr una definición de caso que capte los episodios de la enfermedad en que no se logre documentar el agente causal mediante criterios específicos, estandarizables, de bajo costo y de uso ubicuo en las diferentes partes del mundo. Con el nivel de pragmatismo que exige este complejo problema, la radiografía de tórax ha llegado a aceptarse como el instrumento que mejor reúne estos requisitos. Esta conclusión se sustenta en varias razones. En primer lugar -y teniendo en cuenta que la neumonía es una entidad nosológica que se caracteriza por la presencia de un proceso inflamatorio agudo del pulmón-, la imagen radiológica del tórax constituye la prueba más directa para documentar el sustrato anatomopatológico patognomónico de la enfermedad (con la excepción de los pocos casos en que se logra un estudio histológico del parénquima pulmonar). En segundo lugar, aun cuando la imagen radiológica carece de la sensibilidad y la especificidad suficientes para decidir la conducta terapéutica en un paciente en particular, se reconoce que en los extremos del espectro de las manifestaciones radiológicas de las neumonías predominan etiologías distintas. Así, mientras que los casos que se acompañan de imágenes reticulares y lineales difusas (las cuales apuntan a un predominio del proceso inflamatorio en el compartimiento intersticial) con frecuencia obedecen a causas virales (29-33), las neumonías con signos radiológicos de afección pleural o con infiltrados focales densos, indicadores de una consolidación del espacio aéreo alveolar, suelen obedecer a causas bacterianas (16-21, 30-33).

Además de lo discutido, las razones más contundentes y actuales para asociar la neumonía consolidante (o con afección pleural) con agentes bacterianos han surgido de los estudios de campo con vacunas conjugadas contra $H i b$ realizados en Gambia (34) y Chile (35), y del estudio de eficacia de la vacuna conjugada heptavalente contra $S$. pneumoniae en lactantes de California, Estados Unidos (36). Tanto en Chile como en Gambia, los episodios de neumonía condensante o con derrame pleural (sin documentación etiológica) fueron 20 a $25 \%$ menos frecuentes en los lactantes que recibieron la vacuna conjugada contra Hib que en el grupo testigo, de lo que se infiere que en estas poblaciones entre 20 y $25 \%$ de las hospitalizaciones por los problemas citados obedecían al agente causal específico - Hib - contra el cual confiere protección esta vacuna conjugada. Los datos provenientes del estudio de California apuntan en el mismo sentido: en el primer análisis de los resultados de este estudio (37), los lactantes que recibieron la vacuna conjugada heptavalente contra $S$. pneumoniae tuvieron un riesgo $70 \%$ menor de desarrollar un episodio de neumonía con consolidación que los asignados al grupo testigo, de lo que se puede deducir que esta misma proporción de casos, como mínimo, fue causada por variantes antigénicas de $S$. pneumoniae prevenibles con la vacuna.

Aun si se acepta que la radiografía de tórax permite un diagnóstico razonablemente específico del carácter bacteriano del agente causal, es imprescindible reconocer que su interpretación es relativamente subjetiva, ya que la variabilidad interobservador es un hecho ampliamente documentado (38- 40). Además, la interpretación con fines epidemiológicos exige una mayor especificidad que la adoptada habitualmente en la práctica clínica, donde la seguridad del paciente aconseja extremar la sensibilidad de la observación. Por consiguiente, para utilizar la radiografía de tórax como instrumento de estudio epidemiológico es necesario realizar un cuidadoso trabajo de estandarización orientado a aumentar la concordancia entre las interpretaciones de distintos observadores.

\section{APORTES DEL GRUPO DE INVESTIGADORES DE LOS ESTUDIOS DE CAMPO CON VACUNAS CONTRA NEUMONÍAS, DE LA OMS}

Hace alrededor de dos años, un grupo internacional de investigadores convocados por la OMS se dio a la tarea de establecer un conjunto de criterios y definiciones para la interpretación de las radiografías de tórax de niños con neumonía, de modo que estas se puedan utilizar de forma comparable, tanto en estudios epidemiológicos como en los ensayos que evalúan la eficacia de intervenciones dirigidas al control de las neumonías infantiles en diferentes regiones y países del mundo (9).

El plan de trabajo conjunto entre la OPS y el CVD-Chile que se describe a continuación se desarrolló en estricto apego a las definiciones, criterios y recomendaciones del Grupo de Investigadores de los Estudios de Campo con Vacunas contra Neumonías (Pneumonia Vaccine Trial Investigators' Group), de la OMS (9). De esta forma, las autoridades de salud pública de los países de la Región podrán combinar la información epidemiológica local con las pruebas que arrojen los estudios de eficacia de vacunas que se realicen en otras regiones del mundo, y estimar el impacto que tendría en sus respectivos países la adopción de vacunas contra agentes causantes de neumonías bacterianas.

\section{Plan de trabajo conjunto entre la OPS y el CVD-Chile}

La División de Vacunas e Inmunización de la OPS y el CVDChile acordaron colaborar en la 
promoción de la vigilancia epidemiológica de neumonías presuntamente bacterianas en países latinoamericanos, basándose en criterios y definiciones aceptadas internacionalmente, combinadas con herramientas y soluciones prácticas ajustadas a la realidad de la Región. Con esa finalidad se convino realizar tres talleres subregionales de difusión y capacitación, dirigidos a autoridades de salud pública, epidemiólogos, médicos clínicos y radiólogos que prestan atención a niños con infecciones respiratorias. El primero de los talleres tuvo lugar en Santiago, Chile, en mayo de 2000; el segundo se realizó en San José, Costa Rica, en febrero de 2001; y el tercero se celebró en Guadalajara, México, en abril del mismo año. Cada taller tuvo una duración de 1-2 días y en todos hubo una combinación de exposiciones teóricas y sesiones interactivas. A estas actividades asistieron en total más de 70 profesionales de Argentina, Bolivia, Brasil, Colombia, Costa Rica, Cuba, Chile, México, Paraguay, Perú, Uruguay y Venezuela.

En cada taller se expuso el marco teórico de la vigilancia de neumonías bacterianas - discutido en la primera parte de este informe-, se revisaron las condiciones técnicas básicas para la obtención de radiografías de tórax en niños, y se analizaron los requisitos para utilizar este examen como instrumento epidemiológico. Aprovechando la presencia de epidemiólogos y autoridades de salud pública, los asistentes discutieron modelos de vigilancia susceptibles de ser aplicados en diferentes escenarios asistenciales, así como el tipo de información que se derivaría de cada uno de ellos.

Objetivos. Además de los elementos generales delineados más arriba, el plan de trabajo contempló cuatro objetivos específicos destinados a demostrar la importancia de estandarizar la interpretación de las radiografías de tórax y a compartir herramientas y soluciones prácticas, como apoyo a los estudios epidemiológicos sobre las neumonías infantiles. Estos objetivos específicos fueron abordados mediante sesiones prácticas durante los talleres y sesiones de intercambio posteriores, como se detalla a continuación.

Objetivo 1. Definición operativa de "neumonía presuntamente bacteriana". Para los propósitos de esta iniciativa, un caso de neumonía presuntamente bacteriana se define como un episodio de morbilidad clínicamente compatible con IRA baja acompañado de una radiografía de tórax que muestre infiltrados alveolares densos en una parte de un lóbulo pulmonar, todo un lóbulo o todo un pulmón. Estos infiltrados suelen contener zonas de broncograma aéreo y pueden asociarse con un derrame pleural.

Objetivo 2. Demostración de la necesidad de aplicar criterios y definiciones estándares para interpretar las radiografías de tórax en estudios epidemiológicos de neumonías. Para complementar la argumentación teórica presentada en cada taller, un radiólogo pediatra (KM) expuso los criterios y definiciones propuestos por el Grupo de Investigadores de los Estudios de Campo con Vacunas Contra Neumonías (9) y posteriormente invitó a los asistentes a participar en un ejercicio práctico de interpretación de imágenes. Para ello se presentó una serie de 40 a 44 imágenes de radiografías de tórax obtenidas de niños chilenos hospitalizados por sospecha de neumonía. Las imágenes habían sido previamente digitalizadas mediante fotografía digital. Organizados en grupos de tres a cuatro lectores, los asistentes formularon un informe de consenso para cada imagen en términos de la presencia o ausencia de neumonía condensante y registraron sus informes en un formulario diseñado de antemano. Paralelamente, un radiólogo pediatra del equipo organizador y un radiólogo seleccionado entre el grupo de asistentes emitieron un informe de referencia para cada imagen radiológica, también por consenso entre ambos. Los informes se introdujeron en una base de datos y se calcularon los porcentajes de discordancia y el nivel de concordancia (kappa) de cada grupo de observadores con respecto al informe de referencia emitido por el panel de radiólogos. Los resultados del análisis (cuadro 1) fueron presentados a los asistentes, quienes tuvieron la posibilidad de comparar sus informes y de discutir sus discrepancias con el panel de radiólogos.

Como se aprecia en el cuadro 1 , aun cuando el ejercicio se basó en definiciones y criterios previamente acordados, 21 de los 35 grupos de lectores $(60 \%)$ discreparon con el panel de radiólogos en más de $25 \%$ de los casos al informar de la presencia o ausencia de neumonía condensante en las imágenes. Este ejercicio permitió a los asistentes apreciar de forma directa la variabilidad interobservador que puede presentarse al interpretar radiografías de tórax y la necesidad de ejercitar la aplicación de criterios y definiciones estándares antes de utilizar este examen como instrumento para la vigilancia epidemiológica de neumonías.

Los asistentes a los talleres acordaron establecer contacto con centros que pudieran poner en marcha actividades para la vigilancia de neumonías condensantes en sus respectivos países y aceptaron actuar como monitores para difundir los criterios y definiciones estándares entre los profesionales interesados. Para ello, al término de cada reunión se distribuyó un documento con los criterios de interpretación y las definiciones discutidos durante el taller, más una colección de 100 a 120 imágenes de radiografías de tórax obtenidas de niños con sospecha de neumonía, digitalizadas mediante fotografía digital. Los monitores utilizaron este material para reproducir la metodología demostrada durante los talleres y solicitaron un informe por consenso a cada centro interesado en desarrollar actividades para la pesquisa epidemiológica de neumonías bacterianas. Posteriormente los informes fueron 
CUADRO 1. Concordancia entre la interpretación de imágenes digitalizadas de radiografías de tórax efectuada por lectores de los talleres subregionales y un informe de consenso emitido por dos radiólogos pediatras. Santiago, Chile, 2000-2001

\begin{tabular}{|c|c|c|c|c|c|c|}
\hline Lectores & $\begin{array}{l}\text { Resultados } \\
\text { negativos } \\
\text { falsos }\end{array}$ & $\begin{array}{l}\text { Resultados } \\
\text { positivos } \\
\text { falsos }\end{array}$ & $\begin{array}{c}\text { Resultados } \\
\text { negativos } \\
\text { verdaderos }\end{array}$ & $\begin{array}{l}\text { Resultados } \\
\text { positivos } \\
\text { verdaderos }\end{array}$ & Карра & $\begin{array}{c}\text { Discre- } \\
\text { pancia } \\
(\%)\end{array}$ \\
\hline \multicolumn{7}{|c|}{$\begin{array}{l}\text { Taller 1: Panel } 24 \text { negativos, } \\
16 \text { positivos }\end{array}$} \\
\hline 2 & 5 & 1 & 23 & 11 & 0,67 & 15,0 \\
\hline 3 & 7 & 4 & 20 & 9 & 0,41 & 27,5 \\
\hline 4 & 0 & 9 & 15 & 16 & 0,57 & 22,5 \\
\hline 5 & 2 & 4 & 20 & 14 & 0,69 & 15,0 \\
\hline 6 & 5 & 2 & 22 & 11 & 0,62 & 17,5 \\
\hline 7 & 2 & 5 & 19 & 14 & 0,65 & 17,5 \\
\hline 8 & 2 & 2 & 22 & 14 & 0,79 & 10,0 \\
\hline 9 & 3 & 3 & 21 & 13 & 0,69 & 15,0 \\
\hline 10 & 6 & 6 & 18 & 10 & 0,38 & 30,0 \\
\hline 12 & 2 & 9 & 15 & 14 & 0,47 & 27,5 \\
\hline 13 & 6 & 0 & 24 & 10 & 0,67 & 15,0 \\
\hline 14 & 3 & 4 & 20 & 13 & 0,64 & 17,5 \\
\hline \multicolumn{7}{|c|}{$\begin{array}{l}\text { Taller 2: Panel } 25 \text { negativos, } \\
19 \text { positivos }\end{array}$} \\
\hline 1 & 2 & 3 & 22 & 17 & 0,77 & 11,4 \\
\hline 2 & 3 & 11 & 12 & 18 & 0,37 & 31,8 \\
\hline 3 & 8 & 5 & 16 & 15 & 0,41 & 29,5 \\
\hline 5 & 5 & 11 & 12 & 16 & 0,28 & 36,4 \\
\hline 6 & 5 & 11 & 12 & 16 & 0,28 & 36,4 \\
\hline 7 & 3 & 12 & 13 & 16 & 0,34 & 34,1 \\
\hline 8 & 4 & 10 & 13 & 17 & 0,37 & 31,8 \\
\hline 10 & 10 & 9 & 14 & 11 & 0,13 & 43,2 \\
\hline \multicolumn{7}{|c|}{$\begin{array}{l}\text { Taller 3: Panel } 25 \text { negativos, } \\
19 \text { positivos }\end{array}$} \\
\hline L1C & 4 & 6 & 20 & 14 & 0,54 & 22,7 \\
\hline L1D & 7 & 5 & 21 & 11 & 0,43 & 27,3 \\
\hline L2C & 5 & 8 & 18 & 13 & 0,40 & 29,5 \\
\hline L2D & 8 & 5 & 21 & 10 & 0,37 & 29,5 \\
\hline L3C & 3 & 9 & 17 & 15 & 0,46 & 27,3 \\
\hline L3D & 6 & 5 & 21 & 12 & 0,48 & 25,0 \\
\hline L4C & 6 & 6 & 20 & 12 & 0,44 & 27,3 \\
\hline L4D & 3 & 7 & 19 & 15 & 0,55 & 22,7 \\
\hline L5C & 3 & 8 & 18 & 15 & 0,50 & 25,0 \\
\hline L5D & 6 & 13 & 13 & 12 & 0,16 & 43,2 \\
\hline L6C & 12 & 0 & 26 & 6 & 0,37 & 27,3 \\
\hline L6D & 5 & 7 & 19 & 13 & 0,45 & 27,3 \\
\hline L7C & 6 & 8 & 18 & 12 & 0,35 & 31,8 \\
\hline L7D & 7 & 3 & 23 & 11 & 0,51 & 22,7 \\
\hline L8C & 9 & 4 & 22 & 9 & 0,36 & 29,5 \\
\hline
\end{tabular}

remitidos al CVD-Chile, donde se realizó un nuevo análisis de concordancia entre los informes entregados por los lectores y los informes de referencia emitidos según el consenso de dos radiólogos pediatras. En el cuadro 2 se exponen los resultados de estos análisis en los 11 centros que remitieron informes sobre la serie de imágenes distribuidas al final de los talleres. En este ejercicio, corporal que normalmente es estéril confirma que estamos ante una enfermedad invasora. Los clínicos, epidemiólogos o microbiólogos interesados en divulgar los resultados de sus estudios sobre enfermedades invasoras deben conservar las pruebas bacteriológicas de cada caso, de tal manera que estas puedan ser confirmadas por uno o más laboratorios de referencia o estén disponibles para el escrutinio de sus pares en la comunidad científica. El mismo concepto es aplicable a la imagen radiográfica, si esta se utiliza para confirmar un caso de neumonía.

En la práctica, sin embargo, conservar las radiografías puede resultar más difícil que reproducir y almacenar aislamientos bacterianos. En primer lugar, la radiografía de tórax es un examen necesario para el control médico inmediato $y$ el seguimiento de los pacientes con neumonía, y por lo tanto no puede ser extraída de la historia clínica; segundo, aunque reproducir la placa radiológica es técnicamente posible, ello supone equipos y costos que no son despreciables. Por otra parte, muchos establecimientos asistenciales carecen de espacio o de sistemas de archivo para almacenar ordenadamente las radiografías, por lo que estas suelen ser entregadas a los pacientes o simplemente eliminadas. Aunque no hay dudas de que los equipos radiológicos digitales resuelven fácilmente este problema, es necesario reconocer que la gran mayoría de los establecimientos asistenciales de países latinoamericanos no disponen de ellos hasta ahora.

En el CVD-Chile se adoptó un procedimiento práctico y de bajo costo para almacenar las confirmaciones radiográficas de los casos de neumonía, basado en fotografías digitales de las placas analógicas (41). Con algunas precauciones básicas, esta técnica permite crear archivos digitales que pueden ser reproducidos y almacenados en discos compactos; distribuidos para solicitar las opiniones de otros lectores cuando existan discrepancias de interpretación entre los lectores primarios; 
CUADRO 2. Concordancia entre la interpretación de imágenes digitalizadas de radiografías de tórax distribuidas por los países después de los talleres subregionales y el informe de consenso emitido por un panel de radiólogos pediatras. Santiago, Chile, 2000-2001

\begin{tabular}{|c|c|c|c|c|c|c|}
\hline Centro lector & $\begin{array}{l}\text { Resultados } \\
\text { negativos } \\
\text { falsos }\end{array}$ & $\begin{array}{l}\text { Resultados } \\
\text { positivos } \\
\text { falsos }\end{array}$ & $\begin{array}{c}\text { Resultados } \\
\text { negativos } \\
\text { verdaderos }\end{array}$ & $\begin{array}{l}\text { Resultados } \\
\text { positivos } \\
\text { verdaderos }\end{array}$ & Карра & $\begin{array}{c}\text { Discre- } \\
\text { pancia } \\
(\%)\end{array}$ \\
\hline \multicolumn{7}{|c|}{$\begin{array}{l}\text { Taller 1: Panel } 40 \text { negativos, } \\
60 \text { positivos }\end{array}$} \\
\hline 1 & 3 & 10 & 30 & 57 & 0,72 & 13,0 \\
\hline 2 & 40 & 1 & 39 & 20 & 0,27 & 41,0 \\
\hline 3 & 22 & 2 & 40 & 36 & 0,54 & 24,0 \\
\hline 4 & 23 & 2 & 38 & 37 & 0,52 & 25,0 \\
\hline \multicolumn{7}{|c|}{$\begin{array}{l}\text { Taller 2: Panel } 59 \text { negativos, } \\
61 \text { positivos }\end{array}$} \\
\hline 1 & 16 & 7 & 51 & 45 & 0,61 & 19,3 \\
\hline 2 & 16 & 12 & 47 & 45 & 0,53 & 23,3 \\
\hline \multicolumn{7}{|c|}{$\begin{array}{l}\text { Taller 3: Panel } 59 \text { negativos, } \\
61 \text { positivos }\end{array}$} \\
\hline 1 & 5 & 25 & 34 & 56 & 0,50 & 25,0 \\
\hline 2 & 28 & 4 & 55 & 33 & 0,47 & 26,7 \\
\hline 3 & 8 & 23 & 34 & 53 & 0,47 & 26,3 \\
\hline 4 & 23 & 5 & 52 & 35 & 0,51 & 24,3 \\
\hline 5 & 21 & 2 & 57 & 40 & 0,62 & 19,2 \\
\hline
\end{tabular}

o compartidos con otros investigadores interesados en examinar las confirmaciones radiológicas de los casos de neumonía notificados en estudios epidemiológicos.

Descripción de la técnica de fotografía digital. La técnica que se utiliza en el CVD-Chile requiere de un equipamiento mínimo que consiste en una cámara digital corriente con resolución igual o mayor a $1028 \infty 728$ píxeles y un negatoscopio radiológico convencional de pantalla blanca. En esta experiencia, varias marcas de cámaras digitales ofrecieron imágenes más oscuras que la placa analógica original, por lo que es recomendable usar un transiluminador con cuatro tubos fluorescentes de 10 vatios, con interruptores independientes, que permitan encender dos o más fuentes luminosas según la penetración de la placa radiológica original. La fotografía debe ser tomada en una habitación suficientemente iluminada (de manera que no se active el flash) y se debe evitar que la fuente de luz ambiental se refleje directamente sobre la pantalla del negatoscopio. La cámara puede ser ubicada en un trípode o sostenida por el operador a la altura de la placa, y la distancia debe ser ajustada de forma manual, cuidando de que todos los elementos anatómicos relevantes (senos costofrénicos, clavículas, pared torácica, etc.) se presenten bien centrados y visibles en la pantalla de cristal líquido de la cámara. Con el fin de reducir a un mínimo la pérdida de resolución, se debe capturar la imagen con la máxima resolución permitida por el equipo y descargarla a la computadora en formato JPEG con la menor compresión que permita el programa computarizado.

Las características de la computadora y del monitor son fundamentales para lograr la visua-lización adecuada de las imágenes digitales. La computadora debe tener una tarjeta gráfica de por lo menos $4 \mathrm{MB}$, capaz de soportar una resolución de $1028 \infty 728$ píxeles o mayor. Obviamente, el monitor deberá proporcionar una resolución comparable. Aun cuando el equipo reúna estas especificaciones técnicas, antes de proceder a revisar las imágenes es imprescindible verificar que la resolución y la discriminación de tonos grises sean las adecuadas. Existen plantillas gráficas especialmente diseñadas para este fin que permiten ajustar la luminosidad y el contraste de la pantalla y verificar la resolución del monitor (42).

Validación de la técnica de fotografía digital. Para examinar la confiabilidad de la técnica de fotografía digital, un radiólogo pediatra (KM) realizó una prueba de concordancia intraobservador (43) con una muestra de 200 radiografías de tórax obtenidas de pacientes con sospecha de neumonía atendidos en el hospital pediátrico de Santiago, Chile. Las radiografías de tórax fueron digitalizadas mediante la técnica fotográfica descrita más arriba, archivadas en un disco compacto y entregadas al radiólogo, quien ofreció un informe de cada imagen digital con arreglo a tres categorías: 1) sin infiltrados pulmonares patológicos (normal); 2) con infiltrados condensantes o derrame pleural; y 3) con infiltrados patológicos no condensantes. Dos meses más tarde el radiólogo examinó las placas originales y volvió a informar sus hallazgos en los mismos términos. Finalmente, un año después del ejercicio inicial, el radiólogo interpretó por segunda vez las placas analógicas. El análisis de la concordancia intraobservador se realizó de forma dicotómica, es decir, se contrastaron los casos de neumonía condensante con los resultados acumulados de las otras dos categorías, tomando el primer informe de las placas analógicas como estándar de oro. Como se observa en el cuadro 3, la concordancia intraobservador fue notablemente alta, tanto para las lecturas de imágenes digitales $(K=0,8$; IC95\%: 0,7 a 0,9), como para el segundo informe de las placas analógicas frente al estándar de oro $(K$ = 0,9; IC95\%: 0,8 a 1,0). Más aun, entre los informes de imágenes digitales y el estándar de oro solo hubo 21 informes discrepantes $(10,5 \%)$, cifra razonablemente cercana a la diferencia de $5 \%$ observada entre las lecturas segunda y primera de las placas radiográficas originales. En ambas comparaciones, este observador obtuvo un nivel de concordancia interno semejante o 
CUADRO 3. Concordancia entre la primera lectura de 200 placas analógicas de radiografías de tórax (estándar de oro), la lectura de sus imágenes digitales y una segunda lectura de las placas analógicas, realizadas por un mismo observador ${ }^{a}$

\begin{tabular}{lccccccc}
\hline & $\begin{array}{c}\text { Resultados } \\
\text { negativos } \\
\text { falsos }\end{array}$ & $\begin{array}{c}\text { Resultados } \\
\text { positivos } \\
\text { falsos }\end{array}$ & $\begin{array}{c}\text { Resultados } \\
\text { negativos } \\
\text { verdaderos }\end{array}$ & $\begin{array}{c}\text { Resultados } \\
\text { positivos } \\
\text { verdaderos }\end{array}$ & $\begin{array}{c}n \\
\text { Discrepancia } \\
(\%)\end{array}$ \\
\hline Primera lectura de las placas analógicas & 0 & 0 & 118 & 82 & 200 & 1,0 & 0 \\
Lectura de las imágenes digitales & 12 & 9 & 109 & 70 & 200 & 0,8 & 10,5 \\
Segunda lectura de las placas analógicas & 4 & 6 & 112 & 78 & 200 & 0,9 & 5,0 \\
\hline
\end{tabular}

a El observador es un radiólogo pediatra.

superior al informado en la literatura con radiografías analógicas (39-41, 43).

De acuerdo con la validación descrita y teniendo en cuenta las ventajas prácticas de la fotografía digital con respecto a otros métodos de digitalización, se consideró que esta técnica puede utilizarse para conservar las confirmaciones radiográficas de los casos de neumonía condensante en estudios epidemiológicos. Sin embargo, se debe señalar que esta validación no respalda el uso de la fotografía digital para fines clínicos y que su confiabilidad para documentar casos de neumonía con infiltrados no condensantes es notablemente inferior (datos no mostrados).

Objetivo 4. Uniformar la nomenclatura médica y la codificación de los episodios de neumonía. La comunidad médica ha desarrollado un vocabulario amplio y abundante en términos alusivos a las IRA y no ha adoptado suficientes precauciones para mantener definiciones universalmente aceptadas. Esto suele acarrear problemas en la interpretación de la literatura foránea y crea dificultades de comunicación entre los clínicos, ya que una misma expresión puede aludir a entidades clínicas diferentes según la interpretación de quien la utilice. Esta práctica también tiene consecuencias fuera del ámbito estrictamente médicoasistencial. Por ejemplo, investigadores del CVD-Chile han detectado que la heterogeneidad de la nomenclatura utilizada para registrar los diagnósticos de egreso de los pacientes con neumonía en la mayoría de los principales hospitales pediátricos de
Santiago crea incoherencias en la codificación y en las estadísticas de morbilidad por estas enfermedades. Además, los diagnósticos consignados por los médicos por lo general no dan cuenta del agente causal de los episodios de neumonía, aun cuando este haya sido documentado.

Así, pese a que los hospitales han hecho importantes inversiones en tecnologías de informática y en métodos de laboratorio para identificar los agentes responsables de las IRA bajas, las estadísticas de morbilidad hospitalaria no permiten obtener información retrospectiva confiable acerca de las causas de estas enfermedades (que representan la primera causa de hospitalización en niños chilenos). Sin duda, estas carencias atentan de forma directa contra la posibilidad de establecer sistemas para el monitoreo sistemático y permanente de las causas de neumonía.

Para explorar si el problema de la nomenclatura y las estadísticas de neumonías se repite en otros países, en el segundo $y$ tercer talleres subregionales se desarrollaron ejercicios para el diagnóstico de casos típicos de neumonía. Los organizadores presentaron las historias clínicas, las imágenes radiológicas y los hallazgos de laboratorio más relevantes de seis pacientes con neumonía atendidos en un hospital pediátrico de Santiago, y después invitaron a los clínicos asistentes a registrar un diagnóstico final para cada caso, del mismo modo en que habitualmente completan el formulario de egreso hospitalario. En la serie presentada había dos casos de neumonía con documentación del agente causal (uno con aislamiento de S. pneumoniae en hemocultivo y otro con identificación del virus respiratorio sincicial en secreción respiratoria), más un tercer caso con elementos radiológicos y de laboratorio muy compatibles con una infección pulmonar bacteriana y un cuarto caso con un cuadro clínico típicamente viral. Tal como se había observado repetidamente en Santiago, los clínicos utilizaron una amplia variedad de vocablos para registrar el diagnóstico de un mismo paciente (neumopatía aguda; neumonía, bronconeumonía, neumonitis viral, bronquiolitis, etc.) y, en los dos casos que tenían un agente causal bien documentado, rara vez dejaron constancia de él en el diagnóstico de egreso.

Después de revisar los resultados del ejercicio de diagnóstico, los asistentes discutieron las repercusiones del uso de una nomenclatura médica heterogénea sobre la calidad de las estadísticas de morbilidad por IRA y reconocieron los inconvenientes que tiene el uso de tales estadísticas para el monitoreo de las causas de neumonía. En síntesis, la mayoría de los participantes estuvieron de acuerdo en la necesidad de uniformar la nomenclatura médica utilizada para registrar los diagnósticos de neumonía y en la importancia de que estos diagnósticos den cuenta de la causa de los episodios cuando el agente causal haya sido debidamente documentado.

Propuesta para uniformar la nomenclatura diagnóstica y la codificación de los episodios de neumonía. En el CVDChile se diseñó un instrumento gráfico 
para facilitar y promover el uso de una nomenclatura médica homogénea, el registro sistemático del agente causal y la codificación coherente de los episodios de neumonía y bronquiolitis en el niño. En el instrumento se define la neumonía como una IRA baja que se acompaña de infiltrados radiológicos indicativos de un proceso inflamatorio pulmonar agudo, y se propone utilizar este único vocablo ("neumonía") para referirse a las IRA que cumplan esta definición radiológica, suprimiendo el uso de otros términos, como "neumonitis", "bronconeumonía", "neumopatía aguda", etc. Asimismo, el instrumento ofrece un repertorio de las causas más frecuentes de neumonía infantil y un catálogo de imágenes radiológicas de referencia, a partir de lo cual el usuario puede seleccionar el diagnóstico preformulado que mejor represente la situación del paciente. Por último, junto a cada diagnóstico se presenta el código asignado por la Clasificación internacional de enfermedades vigente en la actualidad (CIE-10).

Esta propuesta fue presentada y discutida con los expertos que asistieron al segundo y tercer talleres subregionales y con varios grupos de pediatras y especialistas que participaron en actividades similares realizadas en Chile. Luego fue revisada por tres codificadores chilenos con experiencia de trabajo con los códigos CIE-10 y, finalmente, fue sometida a la consideración de dos expertos asesores de la OPS en la Atención Integrada de las Enfermedades Prevalentes de la Infancia (AIEPI). Después de incorporar los aportes recibidos, los resultados se plasmaron en un afiche, en formato de $70 \propto 90 \mathrm{~cm}$, que la OPS

1. Murray CJL, López AD. Mortality by cause for eight regions of the world: Global Burden of Disease Study. Lancet 1997;349:12691276.

2. Berman S. Epidemiology of acute respiratory infections in children of developing countries. Rev Infect Dis 1991;13(Suppl 6): S454-462.

3. Landaverde M, di Fabio JL, Ruocco G, Leal I, de Quadros C. Introduction of a conjugate vaccine against $H i b$ in Chile and Uruguay. Rev Panam Salud Publica 1999;5:200-206.

4. Di Fabio JL, Homma A, De Quadros C. Pan American Health Organization epidemiological surveillance network for Streptococcus pneumoniae serotypes. Microb Drug Resist 1997:3:131-133.

5. Hortal M, Lovgren M, de la Hoz F, Agudelo $\mathrm{CI}$, Brandileone MC, Camou T, et al. and the PAHO SIREVA-Vigía Study Groups. pone al alcance de profesionales y centros asistenciales que deseen utilizarlo como material de apoyo a sus actividades de vigilancia de neumonías o para los fines estadísticos habituales de sus centros asistenciales.

\section{COMENTARIOS}

Las actividades aquí resumidas representan un primer intento por impulsar la vigilancia epidemiológica de neumonías presuntamente bacterianas en niños latinoamericanos y constituyen una continuación coherente de la Iniciativa Regional de Vigilancia de Meningitis y Neumonías Bacterianas, iniciada en 1993 por la División de Vacunas e Inmunización de la OPS.

Los ejercicios de interpretación de imágenes radiográficas realizados durante los talleres y después de ellos pusieron de manifiesto tanto la necesidad como la factibilidad de estandarizar los criterios de interpretación de las radiografías de tórax. Estos ejercicios tuvieron un carácter meramente demostrativo y son insuficientes para garantizar el grado de estandarización necesario para emprender actividades de vigilancia epidemiológica de neumonías bacterianas basadas en la interpretación de radiografías. Los investigadores interesados en emprender estudios de este tipo se beneficiarán de la revisión del programa computarizado de entrenamiento y autoevaluación desarrollado para estos fines por la OMS (10). Esto los acreditará como "lectores estandarizados" cuando tengan que notificar los resultados de

\section{REFERENCIAS}

Antibiotic resistance in Streptococcus pneumoniae in six Latin American countries: 1993-1999 surveillance. Microb Drug Resist 2001;7:391-401.

6. Tomas A, Corso A, Severina EP, EchanizAvilez G, Brandileone MC, Camou T, et al. Molecular epidemiologic characterization of penicillin-resistant Streptococcus pneumoniae invasive pediatric isolates recovered in six Latin American countries: an overview. Microb Drug Resist 1998;4:195-207.

7. Kertesz DA, di Fabio JL, de Cunto Brandileone MC, Castaneda E, Echaniz-Aviles G, Heitmann I, et al. Invasive Streptococcus pneumoniae infections in Latin American children. Clin Infect Dis 1998;26:1355-1361.

8. Di Fabio JL, Castaneda E, Agudelo CI, de la Hoz F, Hortal M, Camou T, et al. Evolution of Streptococcus pneumoniae serotypes and los estudios epidemiológicos de neumonías bacterianas en que hayan utilizado radiografías de tórax como instrumento confirmatorio.

Todo el material utilizado en los talleres subregionales, incluidas las presentaciones de los organizadores, las imágenes digitales utilizadas en los ejercicios de interpretación de imágenes $y$ los documentos con definiciones y pautas de interpretación, puede obtenerse en discos compactos mediante una solicitud al Programa de Acceso a la Tecnología de Vacunas, de la División de Vacunas e Inmunización de la OPS. El afiche para uniformar la nomenclatura médica y la codificación de los episodios de neumonía puede obtenerse por esa misma vía o solicitándolo a los autores (rlagos@ adsl.tie.cl).

Las partes colaboradoras en este plan de trabajo están contemplando realizar una reunión de seguimiento con los centros que hayan iniciado o estén planificando comenzar estudios epidemiológicos de las neumonías bacterianas. Esta reunión final servirá para intercambiar experiencias sobre los adelantos alcanzados hasta ahora y permitirá una visión directa y objetiva del impacto final de este plan de trabajo. La División de Vacunas e Inmunización de la OPS reitera su disposición a apoyar iniciativas locales de vigilancia de neumonías bacterianas e invita a los profesionales y centros interesados a solicitar este apoyo mediante protocolos que incorporen los criterios y procedimientos metodológicos discutidos en este documento.

penicillin susceptibility in Latin America, Sireva-Vigia Group, 1993-1999. Pediatr Infect Dis J 2001;20:959-967.

9. World Health Organization, Department of Vaccines and Biologicals, Pneumonia Vaccine Trial Investigators' Group. Standardization and interpretation of chest radiographs for the diagnosis of pneumonia in children. En: www. who.int/vaccines-documents /DocsPDF01/ www616.pdf.

10. Miranda-Novales G, Solorzano-Santos F, Leanos-Miranda B, Vasquez-Rosales G, Palavox-Torres M, Guiscafre-Gallargo $\mathrm{H}$. Blood culture and respiratory sincytial virus identification in acute respiratory infection. Indian J Pediatr 1999;66:831-836.

11. Cleasson BA, Trollfors B, Brolin L, Granstrom M, Henrichsen J, Jodal U, et al. Etiology of community acquired pneumonia in children 
based on antibody responses to bacterial and viral antigens. Pediatr Infect Dis J 1989;8: 856-862.

12. Nohynek H, Eskola J, Laine E, Halonen P, Ruutu P, Saikku P, et al. The etiology of hospital-treated acute lower respiratory tract infection in children. Am J Dis Child 1991; 145:618-622.

13. Drummdom P, Clark J, Wheeler J, Galloway A, Freeman R, Cant A. Community acquired pneumonia: a prospective UK study. Arch Dis Child 2000;83:408-412.

14. Forgie IM, Campbell H, Lloyd-Evans N, Leinomen M, O’Neill K, Saikku P, et al. Etiology of acute lower respiratory tract infection in children in a rural community in The Gambia. Pediatr Infect Dis J 1992;11:466-473

15. Glerant JC, Hellmuth D, Smith JL, Ducroix JP, Jounieaux V. Utility of blood culture in community-acquired pneumonia requiring hospitalization; influence of antibiotic treatment before admission. Resp Med 1999:93: 208-212.

16. Falade AG, Mulholland EK, Adegbola RA, Greenwood BM. Bacterial isolates from blood and lung aspirate cultures in Gambian children with lobar pneumonia. Ann Trop Paediatr 1997;17:315-319.

17. Adegbola RA, Falade AG, Sam BE, Aidoo M, Baldeh I, Hazlett D, et al. The etiology of pneumonia in malnourished and wellnourished Gambian children. Pediatr Infect Dis J 1994,13:975-982.

18. Wall RA, Corrah PT, Mabey DC, Greenwood $\mathrm{BM}$. The etiology of lobar pneumonia in the Gambia. Bull World Heath Organ 1986;64: 553-558.

19. Mimica I, Donoso E, Howard JE, Ledermann GW. Lung puncture in the etiological diagnosis of pneumonia. Am J Dis Children 1971; 122:278-282

20. Shann F, Gratten M, Germer S, Linnemann V, Hazlett D, Payne R. Aetiology of pneumonia in children in Goroka hospital, Papua New Guinea. Lancet 1984;2:537-541.

21. Kalra SK, Sasidharan T, Vatwani V, Sarkar P. Lung puncture: a diagnostic aid in childhood pneumonia. Indian J Pediatr 1981;18:727-730.

22. Isaacs D. Problems in determining the etiology of community-acquired childhood pneumonia. Pediatr Infect Dis J 1989;8:143-148.

23. Lode $\mathrm{H}$, Schaberg $\mathrm{T}$, Raffenberg M, Mauch $\mathrm{H}$. Diagnostic problems in lower respiratory tract infections. J Antimicrob Chemother 1993; 32(Suppl A):29-37.

24. Shann F. Etiology of severe pneumonia in children in developing countries. Pediatr Infect Dis 1986;5:247-252.

25. Juven T, Mertsila J, Toikka P, Virkki R, Leinonen M, Ruuskanen O. Clinical profile of serologically diagnosed pneumococcal pneumonia. Pediatr Infect Dis J 2001;20:1028-1033.

26. Heiskanen-Kosma T, Korppi M, Jokinen $C$, Kurki S, Heiskanen L, Juvonen H, et al. Etiology of childhood pneumonia: serologic results of a prospective, population-based study. Pediatr Infect Diss J 1998;17:986-991.

27. Vouri E, Peltola H, Kallio M, Leinonen M, Hedman K. Etiology of pneumonia and other common childhood infections requiring hospitalization and parenteral antimicrobial therapy. Clin Infect Dis 1998;27:566-572.

28. Korppi M, Leinonen M. Pneumococcal immune conplexes in the diagnosis of lower respiratory infections in children. Pediatr Infect Dis J 1998;17:992-995.

29. Korppi M, Kiekara O, Heiskanen-Kosma T, Soimakallio S. Comparison of radiologic findings and microbiological aetiology of childhood pneumonia. Acta Pediatr 1993;82:360- 363.

30. Swingler GH. Radiological differentiation between bacterial and viral lower respiratory infection in children: a systematic literature review. Clin Pediatr (Phila) 2000;39:627-633.

31. Swischuk LE, Hayden CK. Viral vs bacterial pulmonary infection in children (is roentgenographic differentiation possible?) Pediatr Radiol 1986;16:278-284

32. Alario A, McCarthy P, Markowitz R, Korngutj $\mathrm{P}$, Rosenfield N, Leventhal J. Usefulness of chest radiograph in children with acute lower respiratory tract disease. J Pediatr 1987;111(2): 113-187.

33. Wahlgren $H$, Mortensson W, Eriksson $M$, Finkel Y, Forsgren M. Radiographic patterns and viral studies in childhood pneumonia at various ages. Pediatr Radiol 1995;25:627-630.

34. Mulholland K, Hilton S, Adegbola R, Usen S, Oparaugo A, Omosigho C, et al. Randomised trial of Haemophilus influenzae type $\mathrm{b}$ tetanus protein conjugate vaccine for prevention of pneumonia and meningitis in Gambian children. Lancet 1997,349:1191-1197.

35. Levine OS, Lagos R, Munoz A, Villaroel J, Alvarez AM, Abrego P, et al. Defining the burden of pneumonia in children preventable by vaccination against Haemophilus influenzae type b. Pediatr Infect Dis J 1999;18:1060-1064.

36. Back S, Shinefield H. Efficacy, safety and immunogenicity of heptavalent pneumococcal conjugate vaccine in children. Pediatr Infect Dis J 2000;19:187-195.

37. Shinefield H, Back S. Efficacy of pneumococcal conjugate vaccines in large field trials. Pediatr Infect Dis J 2000;19:394-397.

38. Davies HD, Wang EE, Manson D, Babyn P, Shuckett B. Reliability of the chest radiograph in the diagnosis of lower respiratory infections in young children. Pediatr Infect Dis J 1996;15:600-604.

39. Keikara O, Korppi M, Tanska A, Soimakallio S. Radiological diagnosis of pneumonia in children. Ann Med 1996;28:69-72.

40. Swingler GH. Observer variation in chest radiography of acute lower respiratory infection in children: a systematic review. BMC Medical Imaging 2001;1:1. Disponible en: http:// www.biomedcentral.com/1471.2342/1/1

41. Whitehouse RW. Use of digital camera for radiographs: how to get the best pictures. J $\mathrm{R}$ Soc Med 1999:92:178-182.

42. Plantillas SMPTE y GRAY SCALE. Puede consultarse en: http://brighamrad.harvard. edu/research/topics/vispercep/smpte

43. Cohen J. A coefficient of agreement for nominal scales. Educ Psychol Meas 1960;20:37-46.

Manuscrito recibido el 2 de mayo de 2002. Aceptado para publicación, tras revisión, el 10 de noviembre de 2002.

ABSTRACT The Division of Vaccines and Immunization of the Pan American Health Organization (PAHO) is promoting epidemiological surveillance of bacterial pneumonias in children in Latin America in order to generate scientific evidence to support future decisions concerning using vaccines to control

The use of chest Xrays for surveillance of bacterial pneumonias in children in Latin America such pneumonias in the countries of the Region of the Americas. The diagnosis of these diseases rarely includes bacteriological documentation of the causative agent. Therefore, studies of this type that are carried out around the world accept radiological images of alveolar consolidation as a confirmatory criterion for a presumptively bacterial pneumonia.

This piece examines the theoretical rationale and requirements for using thorax radiology as an instrument for epidemiological surveillance of bacterial pneumonias. The piece also summarizes the activities carried out during 2 years of joint efforts between the Center for Vaccine Development (Centro para Vacunas en Desarrollo) of Chile and PAHO's Division of Vaccines and Immunization. During those 2 years, the two groups encouraged the epidemiological study of bacterial pneumonias in Latin American children, using internationally accepted criteria and definitions as well as tools and practical solutions adapted to the reality of the Region of the America. The activities carried out so far show both the need for and the feasibility of standardizing the interpretation of chest radiographs so that they can be used in epidemiological studies. 